\title{
Comparison of the influence on renal function between cefepime and cefpirome
}

\author{
MINGZI JIANG ${ }^{1}$, JING YAO ${ }^{2}$, LI ZHANG ${ }^{3}$, TIANMING GAO ${ }^{2}$, \\ YANG ZHANG $^{2}$, XIAOQING WENG ${ }^{2}$ and GANZHU FENG ${ }^{2}$
}

\author{
${ }^{1}$ Department of Respiratory Medicine, The First People's Hospital of Kunshan City, Affiliated to \\ Jiangsu University, Kunshan, Jiangsu 215300; Departments of ${ }^{2}$ Respiratory Medicine and ${ }^{3}$ Pharmacy, \\ The Second Affiliated Hospital of Nanjing Medical University, Nanjing, Jiangsu 210000, P.R. China
}

Received January 5, 2015; Accepted January 30, 2015

DOI: $10.3892 /$ br.2015.528

\begin{abstract}
Although known for their broad spectrum and curative efficacy on drug-resistant pathogens and as nephrotoxicity-free, impairments were observed on renal function during clinical treatment of the two most commonly used fourth-generation cephalosporins: Cefpirome and cefepime. The present study aimed to further explore the exact influences of them on renal function. In vitro, the cell viability of renal cells cultured in drug-combined medium was tested for six dilutions. In vivo, a clinical cohort study was carried out to detect the influence of cefpirome and cefepime on the serum creatinine ( $\mathrm{SCr}$ ) level of patients. Cefpirome had an inhibition rate with half maximal inhibitory concentration $\left(\mathrm{IC}_{50}\right)$ of $143.5 \mu \mathrm{mol} / 1$ on renal mesangial cells, which was greater compared to the $\mathrm{IC}_{50}$ of $7.702 \mu \mathrm{mol} / 1$ for cefepime. The clinical cohort study data revealed that cefpirome treatment could lead to a greater increase of the average $\mathrm{SCr}$ level compared to cefepime on days 3 and 7 during therapy, and in addition, a greater incidence of $\mathrm{SCr}>445 \mu \mathrm{mol} / 1$, an indicator of clinical renal failure. Furthermore, patients with an average age $>65$ years were observed as more susceptible to an $\mathrm{SCr}$ rise caused by either cefpirome or cefepime, with a larger augment in the average $\mathrm{SCr}$, as well as a higher incidence of $\mathrm{SCr}>445 \mu \mathrm{mol} / 1 \mathrm{compared}$ to patients aged $<65$ years. In conclusion, cefpirome may have more potential to cause renal impairment compared to cefepime, therefore, more caution and comprehensive analysis of patient conditions is required during the clinical choice of fourth-generation cephalosporins.
\end{abstract}

Correspondence to: Dr Ganzhu Feng, Department of Respiratory Medicine, The Second Affiliated Hospital of Nanjing Medical University, 121 Jiangjiayuan Road, Nanjing, Jiangsu 210000, P.R. China

E-mail: fenggz@njmu.edu.cn

Key words: renal function, fourth-generation cephalosporins

\section{Introduction}

The cephalosporin nucleus has proved to be significantly amenable to modification, allowing more derivatives with different properties. The fourth-generation cephalosporins have been noted for their stability to $\beta$-lactamase enzymes, with a markedly reduced affinity for $\beta$-lactamase and increased outer membrane permeability compared to third-generation cephalosporins, thus making them widely used in clinical infectious diseases. A review of clinical studies indicates that fourth-generation cephalosporins are potentially useful as a first-line empiric therapy for serious infections, including severe community-acquired and nosocomial pneumonia, bacteremia, febrile episodes in neutropenic patients and meningitis (1). Among them, cefepime and cefpirome were most available due to their well-balanced antibacterial spectrum (2).

Previous studies mostly focused on the efficacy of fourth-generation cephalosporins; however, few clinical studies reported their associated renal function adverse effects (3-5). Cefpirome caused nephrotoxic symptoms in a rabbit model and the results suggested that cefpirome is potentially nephrotoxic compared to cefazolin, particularly in a single administration (6,7). Additionally, for the clinical patients at the top three hospitals in Nanjing, the serum creatinine ( $\mathrm{SCr}$ ) level was observed to augment during treatment of cefepime and cefpirome, which indicated the influence associated with fourth-generation cephalosporins on renal function. Therefore, the present study carried out an investigation on the nephrotoxic potential of cefepime and cefpirome in vitro and in a clinical cohort study.

\section{Materials and methods}

In vitro cytotoxicity assay. Renal mesangial cells were used in the cell viability assay. Cells were seeded $12-16 \mathrm{~h}$ before drug treatment at densities of 10,000 cells per well. Six drug dilutions were prepared as follows: 1,000, 100, 10,1,0.1 and $0.01 \mu \mathrm{mol} / 1$. The growth medium without drugs was set as the control group. Each dilution group was tested in five duplicates. The drug solution was added into the wells and cells were cultured at $37^{\circ} \mathrm{C}$ in $5 \% \mathrm{CO}_{2}$. A total of $24 \mathrm{~h}$ later, the drug solution was 
Table I. Clinical characteristics of the patients included in the cohort study.

\begin{tabular}{|c|c|c|c|}
\hline Features & Cefepime $(n=472)$ & Cefpirome $(\mathrm{n}=472)$ & P-value \\
\hline Age, years & & & $>0.05$ \\
\hline$<65$ & 165 & 158 & $>0.05$ \\
\hline$\geq 65$ & 307 & 314 & $>0.05$ \\
\hline Male & 254 & 263 & $>0.05$ \\
\hline Underlying diseases & & & $>0.05$ \\
\hline AECOPD & 213 & 217 & $>0.05$ \\
\hline CAP & 85 & 87 & $>0.05$ \\
\hline Bloodstream infections & 19 & 17 & $>0.05$ \\
\hline Abdominal infection & 47 & 51 & $>0.05$ \\
\hline Skin and soft tissue infection & 21 & 20 & $>0.05$ \\
\hline Urinary system infection & 38 & 41 & $>0.05$ \\
\hline HAP & 49 & 39 & $>0.05$ \\
\hline Complications & & & $>0.05$ \\
\hline Diabetes & 37 & 35 & $>0.05$ \\
\hline Hypertension & 41 & 42 & $>0.05$ \\
\hline Coronary heart disease & 51 & 51 & $>0.05$ \\
\hline Malignant tumor & 19 & 21 & $>0.05$ \\
\hline Cerebral stroke & 31 & 34 & $>0.05$ \\
\hline Cases treated according to drug-sensitivity test & 179 & 181 & $>0.05$ \\
\hline Cases treated according to clinical experience & 293 & 291 & $>0.05$ \\
\hline Cases with satisfactory bacterial eradication & 157 & 161 & $>0.05$ \\
\hline Cases with controlled infection & 370 & 367 & $>0.05$ \\
\hline
\end{tabular}

AECOPD, acute exacerbation of chronic obstructive pulmonary disease; CAP, community-acquired pneumonia; HAP, hospital-acquired pneumonia.

removed and each well was fed with fresh medium containing 3-(4,5-dimethylthiazol-2-yl)-2,5-diphenyltetrazolium bromide (MTT) and incubated for another $4 \mathrm{~h}$. The medium and MTT were removed and the MTT-formazan crystals were dissolved by dimethyl sulfoxide. The optical values were tested at $570 \mathrm{~nm}$. Data were analyzed by SPSS version 18.0 (SPSS, Inc., Chicago, IL, USA) and Graphpad prism 5.0 software (GraphPad Software, Inc., La Jolla, CA, USA).

Clinical cohort study. A total of 944 hospitalized patients who were randomly selected from a third-grade class-A teaching hospital (the Second Affiliated Hospital of Nanjing Medical University, of Nanjing Medical University, Nanjing, China) between January 2009 and December 2012 were included in the cohort study. The inclusion criteria were patients who needed to receive conventional treatment $(2.0 \mathrm{~g}$ every $12 \mathrm{~h}$ ) of fourth-generation cephalosporin (cefepime or cefpirome) according to clinical diagnosis, additionally with an originally normal renal function and creatinine clearance rate. Excluded criteria included chronic renal insufficiency, nephrotic syndrome, renal transplantation, previous use of aminoglycoside antibiotic drugs, combined-use of antimicrobial agents and previous treatment of nephrotoxic drugs. Patients were divided by drug treatment and among each drug group, patients were divided into two age groups: $<65$ and $\geq 65$ years. The clinical characteristics of patients included are described in Table I.

The renal function of patients was tested by examining the $\mathrm{SCr}$ level before, and on days 3 and 7 during the therapy. Following this, the average levels of $\mathrm{SCr}$ in each group were calculated; the incidence of $\mathrm{SCr}>445 \mu \mathrm{mol} / 1$, as an indicator for potential renal failure, was recorded.

Statistical analysis. $\mathrm{P}<0.05$ was considered to indicate a statistically significant difference.

\section{Results}

Comparison of the effects on cell viability of cefepime and cefpirome on renal mesangial cells. As depicted in Table II and Fig. 1, cefepime and cefpirome showed significant inhibition on cell activity compared to the control group and the inhibition rate was dependent on the drug concentration. In each dilution group, cefpirome exhibited a higher inhibition on cell viability than cefepime, as shown in Table II and Fig. 2. Additionally, the half maximal inhibitory concentration $\left(\mathrm{IC}_{50}\right)$ of the drugs on renal mesangial cells for $24 \mathrm{~h}$ was 143.5 and $7.702 \mu \mathrm{mol} / 1$ for cefepime and cefpirome, respectively. 
Table II. Optical value (OD) at $570 \mathrm{~nm}$ and inhibition rate of drugs on renal mesangial cells treated with cephalosporins.

\begin{tabular}{|c|c|c|c|c|c|c|}
\hline \multirow[b]{2}{*}{$\begin{array}{l}\text { Concentration, } \\
\mu \mathrm{mol} / 1\end{array}$} & \multicolumn{3}{|c|}{ Cefepime } & \multicolumn{3}{|c|}{ Cefpirome } \\
\hline & $\begin{array}{c}\text { Mean } \pm \text { SD } \\
\quad(n=5)\end{array}$ & $\begin{array}{c}\text { P-value } \\
\text { vs. control }\end{array}$ & $\begin{array}{l}\text { Inhibition } \\
\text { rate, } \%\end{array}$ & $\begin{array}{c}\text { Mean } \pm \text { SD } \\
\quad(n=5)\end{array}$ & $\begin{array}{c}\text { P-value } \\
\text { vs. control }\end{array}$ & $\begin{array}{l}\text { Inhibition } \\
\text { rate, } \%\end{array}$ \\
\hline 1,000 & $0.295 \pm 0.056$ & $<0.05$ & $85.99 \pm 2.66$ & $0.067 \pm 0.007$ & $<0.05$ & $96.83 \pm 0.34$ \\
\hline 100 & $1.285 \pm 0.052$ & $<0.05$ & $38.94 \pm 2.45$ & $0.313 \pm 0.013$ & $<0.05$ & $85.13 \pm 0.62$ \\
\hline 10 & $1.818 \pm 0.046$ & $<0.05$ & $13.62 \pm 2.21$ & $1.021 \pm 0.015$ & $<0.05$ & $51.58 \pm 0.71$ \\
\hline 1 & $1.906 \pm 0.026$ & $<0.05$ & $9.42 \pm 1.22$ & $1.636 \pm 0.029$ & $<0.05$ & $22.38 \pm 1.39$ \\
\hline 0.1 & $2.030 \pm 0.082$ & $<0.05$ & $3.53 \pm 3.91$ & $1.930 \pm 0.011$ & $<0.05$ & $8.46 \pm 0.53$ \\
\hline 0.01 & $2.042 \pm 0.014$ & $>0.05$ & $2.97 \pm 0.67$ & $2.003 \pm 0.013$ & $<0.05$ & $4.98 \pm 0.60$ \\
\hline Control & $2.105 \pm 0.015$ & & & $2.108 \pm 0.009$ & & \\
\hline $\mathrm{IC}_{50}, \mu \mathrm{mol} / 1$ & 143.5 & & & 7.702 & & \\
\hline
\end{tabular}

$\mathrm{SD}$, standard deviation; $\mathrm{IC}_{50}$, half maximal inhibitory concentration.
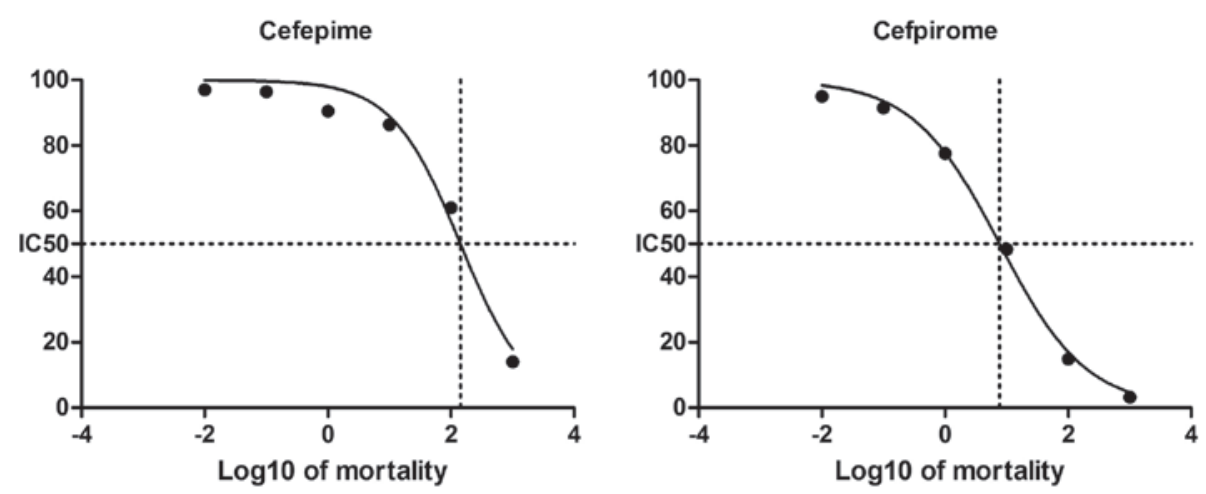

Figure 1. Inhibition of cell viability of renal mesangial cells by the two fourth-generation cephalosporins. $\mathrm{IC}_{50}$ half maximal inhibitory concentration.

\section{Cefepime $(\mu \mathrm{mol} / \mathrm{I})$} 1000
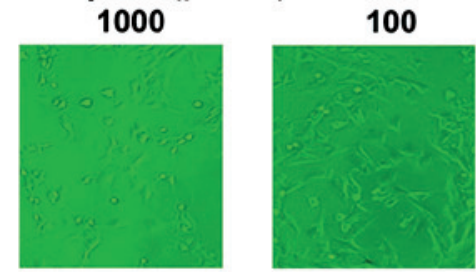

\section{Cefpirome ( $\mu \mathrm{mol} / \mathrm{l})$} 1000

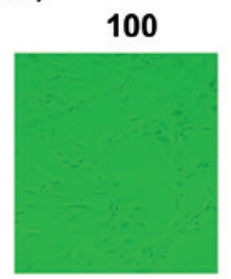

10

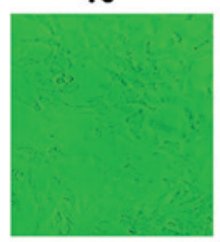

10

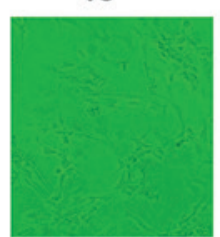

1

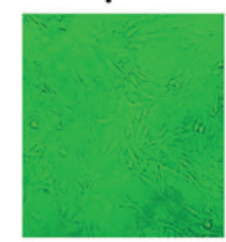

1

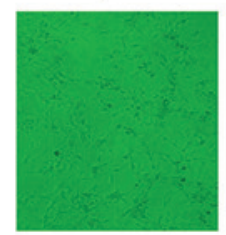

0.1

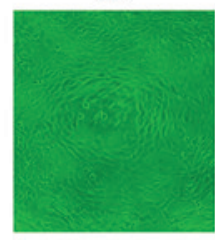

0.1

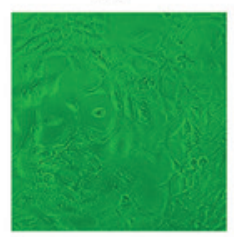

0.01

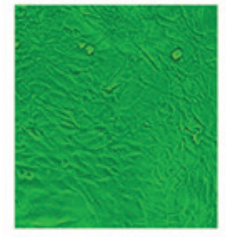

0.01

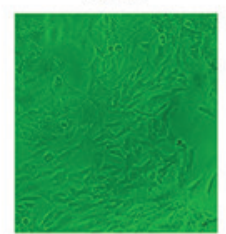

Control

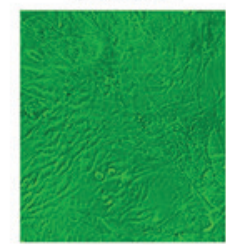

Control

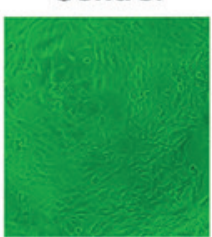

Figure 2. Observation of cells under an optical microscope (magnification, $\mathrm{x} 40$ ).

Changes of serum creatine level following treatment with cefepime or cefpirome. As shown in Table III, treatment of cefepime resulted in a greater increase of $\mathrm{SCr}$ in the two age groups compared to cefpirome. In patients aged $<65$ years, cefepime rose from an average SCr level of $67 \pm 7.4$ to $83 \pm 11.1 \mu \mathrm{mol} / \mathrm{l}$ on day 3 and $87 \pm 10.3 \mu \mathrm{mol} / 1$ on day 7 , while cefpirome augmented an average $\mathrm{SCr}$ level from $65 \pm 8.7$ to $95 \pm 10.9 \mu \mathrm{mol} / 1$ on day 3 and $98 \pm 14.2 \mu \mathrm{mol} / 1$ on day 7 . On 
Table III. Comparison of the changes of serum creatinine levels during treatment of fourth-generation cephalosporins.

Levels of serum creatinine (mean $\pm \mathrm{SD}, \mu \mathrm{mol} / \mathrm{l})$

\begin{tabular}{|c|c|c|c|c|c|c|}
\hline \multirow[b]{2}{*}{ Days during therapy } & \multicolumn{3}{|c|}{ Cefepime } & \multicolumn{3}{|c|}{ Cefpirome } \\
\hline & $\begin{array}{l}<65 \text { years old } \\
\quad(n=165)\end{array}$ & $\begin{array}{c}\geq 65 \text { years old } \\
(n=307)\end{array}$ & P-value & $\begin{array}{c}<65 \text { years old } \\
\quad(\mathrm{n}=158)\end{array}$ & $\begin{array}{c}\geq 65 \text { years old } \\
\quad(n=314)\end{array}$ & P-value \\
\hline Before & $67 \pm 7.4$ & $67 \pm 7.4$ & $>0.05$ & $65 \pm 8.7$ & $65 \pm 8.7$ & $>0.05$ \\
\hline Day 3 & $83 \pm 11.1$ & $91 \pm 11.7$ & $>0.05$ & $95 \pm 10.9$ & $130 \pm 12.4$ & $>0.01,<0.05$ \\
\hline Day 7 & $87 \pm 10.3$ & $102 \pm 11.8$ & $>0.05$ & $98 \pm 14.2$ & $155 \pm 13.1$ & $<0.01$ \\
\hline
\end{tabular}

$\mathrm{SD}$, standard deviation.

Table IV. Comparison of the serum creatinine ( $\mathrm{SCr}$ ) $>445 \mu \mathrm{mol} / \mathrm{l}$ incidences in the two fourth-generation cephalosporins groups.

\begin{tabular}{|c|c|c|c|c|}
\hline \multirow[b]{3}{*}{ Days during therapy } & \multicolumn{4}{|c|}{ Incidence of $\mathrm{SCr}>445 \mu \mathrm{mol} / 1$} \\
\hline & \multicolumn{2}{|c|}{ Cefepime } & \multicolumn{2}{|c|}{ Cefpirome } \\
\hline & $\begin{array}{c}<65 \text { years old, } \mathrm{n}(\%) \\
(\mathrm{n}=165)\end{array}$ & $\begin{array}{l}\geq 65 \text { years old, } \mathrm{n}(\%) \\
(\mathrm{n}=307)\end{array}$ & $\begin{array}{c}<65 \text { years old, } \mathrm{n}(\%) \\
(\mathrm{n}=158)\end{array}$ & $\begin{array}{c}\geq 65 \text { years old, } n(\%) \\
(\mathrm{n}=314)\end{array}$ \\
\hline Before & 0 & 0 & 0 & 0 \\
\hline Day 3 & $0(0.0)$ & $1(0.3)$ & $1(0.6)$ & $4(1.3)$ \\
\hline Day 7 & $1(0.6)$ & $2(0.7)$ & $3(1.9)$ & $10(3.2)$ \\
\hline
\end{tabular}

day 3 , none of the patients suffered from $\mathrm{SCr}>445 \mu \mathrm{mol} / 1 \mathrm{in}$ the cefepime group, but one patient suffered in the cefpirome group (incidence, $0.6 \%$ ). On day 7 , one case in the cefepime group (incidence, $0.6 \%$ ) and two additional cases in the cefpirome group (incidence, $1.9 \%$ ) exhibited $\mathrm{SCr}>445 \mu \mathrm{mol} / 1$, as shown in Table IV.

In patients aged $\geq 65$ years, a higher increase of $\mathrm{SCr}$ was observed for the two drugs. In the cefepime group, the average SCr level was $91 \pm 11.7 \mu \mathrm{mol} / 1$ on day 3 and $102 \pm 11.8 \mu \mathrm{mol} / 1$ on day 7 , while for the cefepime group the level was $130 \pm 12.4$ and $155 \pm 13.1 \mu \mathrm{mol} / 1$ on days 3 and 7 , respectively. Among the $\geq 65$ age group, the incidence of $\mathrm{SCr}>445 \mu \mathrm{mol} / 1$ increased, which was $0.3 \%$ (one case) on day 3 and $0.7 \%$ (two cases) on day 7 for the cefepime group, and $1.3 \%$ (four cases) on day 3 and $3.2 \%$ (10 cases) on day 7 for the cefpirome group, as depicted in Tables III and IV.

\section{Discussion}

As a large group of associated $\beta$-lactam antimicrobial agents, the cephalosporins possess various advantages, including low rates of toxicity, relatively broad activity spectrum and ease of administration on clinical treatment against infectious diseases. Currently, the fourth-generation cephalosporins are used more widely as the drug-resistant condition grows more severe, among which cefpirome and cefepime are the most available and used. Cephalosporins cause renal toxicity and cephaloridine was noted as the most nephrotoxic (8). Corresponding mechanisms include lipid peroxidation, competitive inhibition of mitochondrial carnitine transport, fatty acid oxidation and acylation, and inactivation of tubular cell proteins. The fourth-generation cephalosporins were revealed to cause renal damage in animal models (9-11). Therefore, the potential influence on renal function of fourth-generation cephalosporins should be considered as a matter of concern.

In the present study, cefepime and cefpirome caused significant cytotoxicity on renal mesangial cells and cefpirome with a higher $\mathrm{IC}_{50}$ on cell viability may be more renal cytotoxic than cefepime. Consistent results were observed in the clinical cohort study. Cefpirome was observed to cause a greater elevation of the average $\mathrm{SCr}$ level, as well as the incidence of $\mathrm{SCr}>445 \mu \mathrm{mol} / 1$ compared to the cefepime group. Within each drug group, the $\geq 65$ years subgroup was more susceptive to nephrotoxicity caused by drugs, with a larger increase of the average $\mathrm{SCr}$ levels and higher incidence of $\mathrm{SCr}>445 \mu \mathrm{mol} / 1$. Cefpirome had more potential to induce renal damage compared to cefepime. Future studies should focus on renal interstitial cells, as the majority of observed renal damage caused by cephalosporins are interstitial nephritis. In addition, further clinical indicators associated with renal function are required for a deeper insight of the adverse effects of fourth-generation cephalosporins. Animal models should be designed to well expound the mechanisms of potential nephrotoxicity of fourth-generation cephalosporins.

In conclusion, the two fourth-generation cephalosporins have nephrotoxic potential and cefpirome has a greater 
tendency to cause renal damage. Additional attention should be paid to elder patients. Cefpirome should be a more cautious choice in clinical treatment.

\section{Acknowledgements}

The present study was sponsored by the Health Department of Jiangsu province (grant no. H200911).

\section{References}

1. Garau J, Wilson W, Wood M and Carlet J: Fourth-generation cephalosporins: A review of in vitro activity, pharmacokinetics, pharmacodynamics and clinical utility. Clin Microbiol Infect 3 (Suppl 1): s87-s101, 1997.

2. Gould IM: Do we need fourth-generation cephalosporins? Clin Microbiol Infect 5: S1-S5, 1999.

3. Saito T, Ichinohe T, Kanda J, et al: Historical cohort study of the efficacy and safety of piperacillin/tazobactam versus fourth-generation cephalosporins for empirical treatment of febrile neutropenia in patients with hematological malignancies. Int J Clin Med 2: 18-22, 2011.

4. Hoffman JM, Frediani J, Herr M, Flynn PM and Adderson EE: The safety of cefepime and ceftazidime in pediatric oncology patients. Pediatr Blood Cancer 60: 806-809, 2013.

5. Gonçalves-Pereira J and Póvoa P: Antibiotics in critically ill patients: A systematic review of the pharmacokinetics of $\beta$-lactams. Crit Care 15: R206, 2011.
6. Deki T, Matsuoka A, Marutani K, et al: Nephrotoxicity of cefpirome sulfate in rabbits - single and multiple intravenous administration. J Toxicol Sci 15 (Suppl 3): 173-200, 1990 (In Japanese).

7. Cojocel C: Biochemical aspects of the renal tolerance for cefpirome and other cephalosporins. Arzneimittelforschung 40: 1140-1144, 1990

8. Tune BM: Nephrotoxicity of $\beta$-lactam antibiotics: Mechanisms and strategies for prevention. Pediatr Nephrol 11: 768-772, 1997.

9. Rokushima M, Fujisawa K, Furukawa N, et al: Transcriptomic analysis of nephrotoxicity induced by cephaloridine, a representative cephalosporin antibiotic. Chem Res Toxicol 21: 1186-1196, 2008.

10. Soni A, Chaudhary M and Dwivedi VK: Ceftriaxone-vancomycin drug toxicity reduction by VRP 1020 in Mus musculus mice. Curr Clin Pharmacol 4: 95-101, 2009.

11. Yılmaz N, Ilhan S, Nazıroğlu M, Oktar S, Nacar A, Arıca V and Tutanc M: Ceftriaxone ameliorates cyclosporine A-induced oxidative nephrotoxicity in rat. Cell Biochem Funct 29: 102-107, 2011. 